\title{
The other side of sea level change
}

\author{
Matthias Prange (10 ${ }^{1 凶}$, Thomas Wilke ${ }^{2}$ \& Frank P. Wesselingh ${ }^{3,4}$
}

Water levels in inland seas and lakes globally will drop, often dramatically, over the $21^{\text {st }}$ century in response to climate change. Based on the case of the Caspian Sea, we argue for a concerted campaign to raise awareness of threats to people, biodiversity and geopolitical stability.

Many countries are implementing or planning adaptation measures around sea level rise, following consistent and prominent information from the Intergovernmental Panel on Climate Change $^{1}$ (IPCC). By contrast, the projected impact of global warming on falling water levels in enclosed seas and lake systems due to continental drying in vast regions of the world ${ }^{2-4}$ receives much less attention. Rising surface temperatures will intensify evaporation over land ${ }^{2,3}$ and lakes $^{5}$ during the twenty-first century. These changes act to reduce lake levels and surface areas, and are exacerbated by decreasing precipitation in many regions of the world ${ }^{2,3}$. Endorheic lakes that do not have an outflow are particularly sensitive to climatic change, because their water levels are determined by the delicate balance between precipitation and discharge into the lake and evaporation over the lake surface. While the climate-driven drying of continental interiors is recognized as an important problem in terms of fresh water scarcity ${ }^{6}$, its impact on lake levels will have many other far-reaching consequences that are underappreciated, but affect the livelihoods and economies of millions of people all over the world. A massive warning signal is the projected catastrophic drop in water levels for the Caspian Sea, the largest lake in the world, which could hit stakeholders unprepared.

Here we argue that not enough space has been devoted to the issue of falling water levels in inland seas and lakes worldwide in internationally recognized high-profile efforts, such as the IPCC's Synthesis Reports, the United Nations' Sustainable Development Goals, or the Intergovernmental Science-Policy Platform on Biodiversity and Ecosystem Services (IPBES). The environmental, economic, and political impacts of falling lake levels will be devastating. A global task force is urgently needed to develop and coordinate transboundary mitigation and adaptation strategies.

\section{Caspian catastrophe}

Sea level in the Caspian Sea is projected to fall by 9-18 $\mathrm{m}$ in medium to high emissions scenarios until the end of this century ${ }^{7}$, caused by a substantial increase in lake evaporation that is not balanced by increasing river discharge or precipitation. According to these new projections, twenty-first century Caspian sea level decline will be about twice as large as estimates based on earlier climate models ${ }^{8,9}$. A decline by $9-18 \mathrm{~m}$ will mean that the vast northern Caspian shelf, the Turkmen shelf in the southeast, and all coastal areas in the middle and southern Caspian Sea emerge from under the sea surface. In addition, the Kara-Bogaz-Gol Bay on the eastern margin will be completely desiccated. Overall, the Caspian Sea's surface area will shrink by $23 \%$ for a $9 \mathrm{~m}$ and by $34 \%$ for an $18 \mathrm{~m}$ drop of sea level (see Fig. 1).

${ }^{1}$ MARUM - Center for Marine Environmental Sciences, University of Bremen, Bremen, Germany. ${ }^{2}$ Department of Animal Ecology \& Systematics, Justus Liebig University, Giessen, Germany. ${ }^{3}$ Naturalis Biodiversity Center, Leiden, Netherlands. ${ }^{4}$ Department of Earth Sciences, Utrecht University, Utrecht, The Netherlands. ${ }_{\text {email: }}$ mprange@marum.de 


\section{Biodiversity}

The projected Caspian sea level decline combined with the loss of the highly productive and seasonally ice-covered northern Caspian shelf will severely affect this unique ecosystem, which is already under immense stress due to pollution, over-exploitation and the introduction of invasive species ${ }^{10}$. The reduction in winter sea-ice area will affect pupping grounds for the endangered Caspian seal ${ }^{11}$. The disappearance of the vast shelf further robs the Caspian Sea of shallow-water habitats that are major food sources (e.g., for fish, migrating birds, and the endemic seal), and provide spawning grounds for native and endemic fish species such as the endangered sturgeons.

Current protected areas in the Caspian Sea, most of which cover coastal ecosystems including highly coveted wetlands such as the Volga Delta and other Ramsar sites (wetlands of international importance named after the Caspian coastal city of Ramsar, Iran) will be transformed beyond recognition. Fluvial input of pollutants and surplus nutrients that bypasses the emerged shelf areas will directly impact the central basin. Together with higher productivity driven by higher temperatures, river inputs will reduce oxygen availability. Emerging dead zones will likely affect biodiversity hotspots in both shallow and deeper parts of the Caspian Sea, very similar to the current expansion of such zones in the oceans ${ }^{12}$. The expected escalating effects of Caspian sea level decline are likely to lead to a wholesale reorganization of ecosystems, and threaten unique Caspian biota that have been evolving in the basin over millions of years ${ }^{13}$.

\section{Ecosystem services and economics}

The Caspian Sea ecosystem provides essential benefits to humans, but will be severely affected if Caspian sea levels decline as projected. Implications include a loss of provisioning services, such as shrinking fishing grounds and the drying up of aquaculture facilities; a loss of supporting services such as nutrient cycling; a loss of regulating services, such as the provision of moisture and precipitation to water-stressed Central Asia through evaporation over the lake surface; and a loss of cultural services associated with recreation and tourism. As such, all four categories of ecosystem services outlined by the Millennium Ecosystem Assessment ${ }^{14}$ will be affected. As the livelihoods and food security of millions of people depend on the Caspian Sea, a loss of these ecosystem services will have drastic socioeconomic consequences and may trigger local and regional conflicts-in an ethnically diverse region that is already rife with tensions.

Decreasing Caspian sea level will have geopolitical ramifications and an impact on the economies throughout the region. Shipping traffic inside and outside the Caspian Sea, which is connected to the World Ocean by the Volga-Baltic Waterway and the VolgaDon Canal, will be affected, with consequences for maritime trade and naval access. Coastal infrastructure including ports will become obsolete as waters recede. Shrinkage of the Caspian Sea might further affect future claims by the five littoral states on the coveted oil and gas reserves. Maritime zones of jurisdiction and exclusive fishing rights will shift. Growing international political tensions would be expected regarding the reallocation of fishing grounds or national water extraction and desalination plans ${ }^{15}$ to help meet the increasing demands of the agricultural, industrial, and household sectors in water-stressed regions.

\section{Mitigation and adaptation}

Mitigation and adaptation to Caspian sea level decline will be a challenge for several reasons that similarly applies to declining water levels in lakes and inland seas elsewhere:

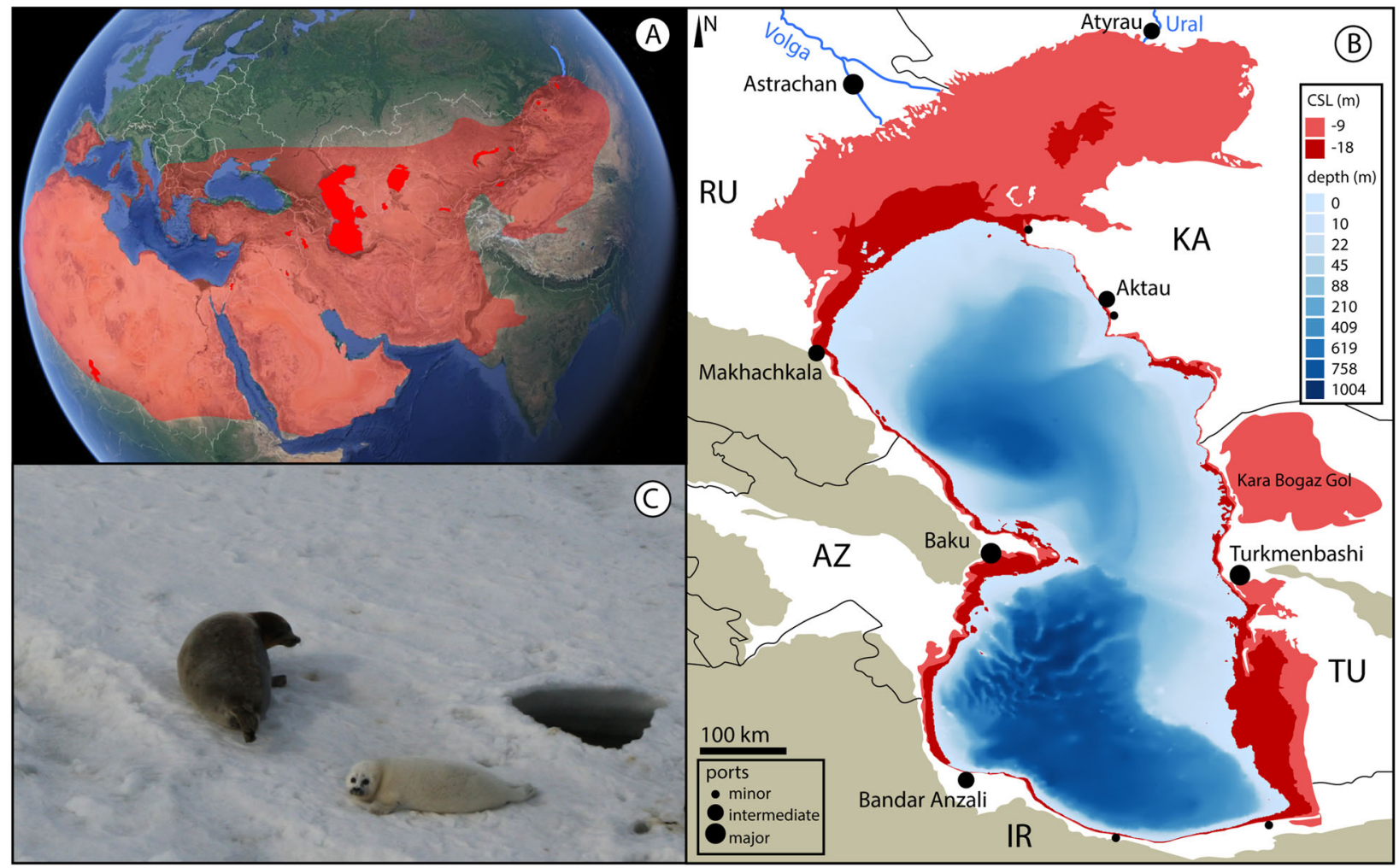

Fig. 1 Caspian sea level fall and its impacts. A Regions affected by severe drying as projected for 2080-2099 (based on ref. ${ }^{2}$ ) with major lakes located in the region indicated in bright red. Many of these lakes are already experiencing drying. Map data: Google Earth, Landsat/Copernicus (data from SIO/NOAA, U.S. Navy, NGA, GEBCO, IBCAO, USGS). B Impact of Caspian Sea Level projections of $-9 \mathrm{~m}$ and $-18 \mathrm{~m}$ at the end of the twenty-first century. Red regions fall dry. C The Caspian seal is one of the endangered, endemic Caspian species that will be severely affected by the emergence of the northern Caspian shelf and reduction of winter sea ice due to rising temperatures. Today, at least $99 \%$ of the pupping grounds are located there (photograph courtesy of Susan Wilson). 
(i) Global versus local: The decline is mainly caused by global factors, but the consequences are regional and local. Global mitigation measures such as greenhouse gas emissions reductions will likely take effect too late, since Caspian sea level is already declining at a rate of about 6-7 $\mathrm{cm}$ per year ${ }^{4}$. Thus, intensified regional adaptation measures are required.

(ii) Awareness gap: There is a lack of awareness among stakeholders that there is a problem. For example, the IPCC's First Assessment Report (1990/92) suggested an increase in Caspian sea level from about 2010 onwards. None of the IPCC Synthesis Reports considers this issue further. Moreover, the inter-governmental Caspian Environment Program assumed in 2011 that the Caspian sea level would fluctuate only slightly in the future ${ }^{16}$. As a result, governance at international, national and regional levels for Caspian Sea-wide adaptation measures to Caspian sea level decline are lacking.

(iii) Lack of studies: Assessment of risks and vulnerability of the Caspian region's ecosystem, economies, and social systems to Caspian sea level decline are largely absent. The problem is exacerbated by received wisdom that sees periodic Caspian sea level fluctuations as a self-regulating phenomenon.

(iv) Spatial optimism bias: Different communities and littoral countries might perceive that they are less affected by Caspian sea level decline than others. Such a bias could hamper coordinated adaptation actions.

The lack of public and political awareness of the imminent Caspian sea level decline applies equally to the worldwide lake level changes driven or amplified by global warming. A growing number of scientific studies predict climate-driven drying in many regions of the world, which will inevitably entail substantial lake level drops in Asian, African, and American basins ${ }^{2-4}$. In addition, lake levels are also affected by human water withdrawals, river damming and diversions (the famous desiccation of the Aral Sea is only one dramatic example for this), which often mask climate impacts ${ }^{17,18}$. Precise models for future climatedriven lake level changes as a scientific basis for anticipatory and sustainable mitigation and adaptation strategies are of paramount importance, but largely lacking ${ }^{19}$.

We therefore call for a global awareness campaign concerning future climate-driven lake level changes. In particular, we propose to pay considerable attention to this issue in future IPCC reports as well as in the next Global Assessment Report by the Intergovernmental Science-Policy Platform on Biodiversity and Ecosystem Services. We also call for scientific programs to assess risks and vulnerability with respect to worldwide lake level decline and to provide guidance in decision-making. Finally, we suggest to establish a global task force to develop and coordinate transboundary mitigation and adaptation strategies, assisted by the recently launched World Adaptation Science Programme (WASP) hosted by the United Nations Environment Programme (UNEP), which is envisaged as an interface between adaptation research and decision makers. International climate funds can offer an opportunity to finance projects and adaptation measures if changes in lake levels are attributed to climate change.

The impacts of the overlooked facet of future sea level changefalling levels of lakes and seas in continental interiors on a global scale-could be similarly devastating as global sea level rise, and threaten the livelihood of millions of people worldwide. Immediate and coordinated action is needed to make up for valuable time lost. The shrinking Caspian Sea might serve as a poster child of the problem that will help to galvanize such actions.

Received: 16 September 2020; Accepted: 25 November 2020; Published online: 23 December 2020

\section{References}

1. Pörtner, H. -O. et al. (Ed.) IPCC Special Report on the Ocean and Cryosphere in a Changing Climate (IPCC (WMO, UNEP), Geneva (Switzerland), 2019).

2. Cook, B. I., Smerdon, J. E., Seager, R. \& Coats, S. Global warming and 21st century drying. Clim. Dyn. 43, 2607-2627 (2014).

3. Dai, A., Zhao, T. \& Chen, J. Climate change and drought: a precipitation and evaporation perspective. Curr. Climate Change Rep. 4, 301-312 (2018).

4. Wang, J. et al. Recent global decline in endorheic basin water storages. Nat. Geosci. 11, 926-932 (2018).

5. Wang, W. et al. Global lake evaporation accelerated by changes in surface energy allocation in a warmer climate. Nat. Geosci. 11, 410-414 (2018).

6. UNESCO (UN-Water). United Nations World Water Development Report 2020: Water and Climate Change. (UNESCO, Paris, 2020).

7. Nandini-Weiss, S. D., Prange, M., Arpe, K., Merkel, U. \& Schulz, M. Past and future impact of the winter North Atlantic Oscillation in the Caspian Sea catchment area. Int. J. Climatol. 40, 2717-2731 (2020).

8. Elguindi, N. \& Giorgi, F. Projected changes in the Caspian Sea level for the 21st century based on the latest AOGCM simulations. Geophys. Res. Lett. 33, L08706 (2006).

9. Renssen, H. et al. Simulating long-term Caspian Sea level changes: the impact of Holocene and future climate conditions. Earth Planet. Sci. Lett. 261, 685-693 (2007).

10. Lattuada, M., Albrecht, C. \& Wilke, T. Differential impact of anthropogenic pressures on Caspian Sea ecoregions. Mar. Poll. Bull. 142, 274-281 (2019).

11. Wilson, S. C. et al. Breeding behavior and pup development of the Caspian seal. Pusa caspica. J. Mammalogy 98, 143-153 (2017).

12. Breitburg, D. et al. Declining oxygen in the global ocean and coastal waters. Science 359, eaam7240 (2018).

13. Krijgsman, W. et al. Quaternary time scales for the Pontocaspian domain: interbasinal connectivity and faunal evolution. Earth Sci. Rev. 188, 1-40 (2019).

14. Millennium Ecosystem Assessment. Ecosystems and Human Well-being: Synthesis. (Island Press, Washington DC, 2005).

15. Tehran Times. Water transfer from Caspian Sea not economically justifiable. Tehran Times https://www.tehrantimes.com/news/433428/Water-transferfrom-Caspian-Sea-not-economically-justifiable (2019).

16. Caspian Environment Programme (CEP). Caspian Sea-State of the Environment (CEP, 2011) https://www.tehranconvention.org/IMG/pdf/ Caspian_SoE_Eng_fin.pdf.

17. Wurtsbaugh, W. A. et al. Decline of the world's saline lakes. Nat. Geosci. 10, 816-821 (2017).

18. Wine, M. L. \& Davison, J. H. Untangling global change impacts on hydrological processes: resisting climatization. Hydrol. Processes 33, 2148-2155 (2019).

19. Woolway, R. I. et al. Global lake response to climate change. Nat. Rev. Earth Environ. 1, 388-403 (2020)

\section{Acknowledgements}

We thank Richard Preece, John Pandolfi, Michael Schulz, Angela Posada-Swafford, Susan Wilson, Simon Goodman, Heiko Prange-Gstöhl, and Helmut Breitmeier for critical feedback. Matteo Lattuada assisted with Fig. 1B and Susan Wilson provided the photograph in Fig. 1C. This research was supported by the project PRIDE (Pontocaspian RIse and DEmise) which has received funding from the European Union's Horizon 2020 research and innovation program, under the Marie Sklodowska-Curie grant agreement No 642973.

\section{Author contributions}

Matthias Prange, Thomas Wilke, and Frank Wesselingh contributed equally to the conceptualization and writing of the paper.

\section{Funding}

Open Access funding enabled and organized by Projekt DEAL.

\section{Competing interests}

The authors declare no competing interests.

\section{Additional information}

Correspondence and requests for materials should be addressed to M.P.

Reprints and permission information is available at http://www.nature.com/reprints

Publisher's note Springer Nature remains neutral with regard to jurisdictional claims in published maps and institutional affiliations. 
(c) (i) Open Access This article is licensed under a Creative Commons Attribution 4.0 International License, which permits use, sharing, adaptation, distribution and reproduction in any medium or format, as long as you give appropriate credit to the original author(s) and the source, provide a link to the Creative Commons license, and indicate if changes were made. The images or other third party material in this article are included in the article's Creative Commons license, unless indicated otherwise in a credit line to the material. If material is not included in the article's Creative Commons license and your intended use is not permitted by statutory regulation or exceeds the permitted use, you will need to obtain permission directly from the copyright holder. To view a copy of this license, visit http://creativecommons.org/ licenses/by/4.0/.

() The Author(s) 2020, corrected publication 2021 